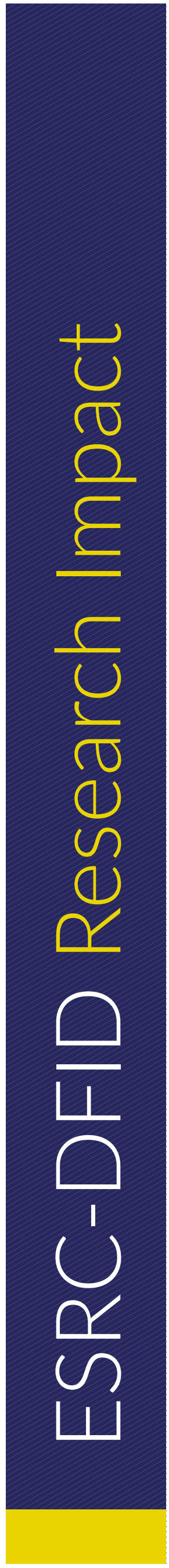

\title{
IMPROVING LITERACY THROUGH INDIGENOUS LANGUAGES IN SOUTH AFRICA
}

To better understand early grade reading in African languages, a multi-disciplinary team of researchers from Stellenbosch University, the University of Cape Town, the University of South Africa and Funda Wande, together with the Department of Basic Education (DBE) in South Africa, are working towards a deeper understanding of higher reading gains in English and three African languages.

\section{THE CHALLENGE}

In South African primary schools, more than three quarters of nine to ten year-olds fail to reach the expected benchmarks in reading. Despite the high proportion of children learning to read in their mother tongue, there is little research on African language reading. This research is contributing to the development of national reading benchmarks in indigenous languages, leading to deeper understanding of how proficiency in African languages can contribute to improved literacy.

\section{THE RESEARCH}

The 'Leadership for Literacy' project was a twoyear (2016-18) mixed-method study that used a combination of case study research and longitudinal data from 60 schools. It aimed to understand the development of early reading skills and how these enable comprehension, what factors underpin success, and how it is similar or different across languages.

Specifically, the team looked at the factors associated with higher reading gains in English and three common African languages (isiZulu, Northern Sotho and Xitsonga) of 756 grade 3 students and 656 grade 6 students in outstanding and low-performing township and rural schools in the provinces of Gauteng,

KwaZulu-Natal and Limpopo.

The team found that many of the children were not reaching basic levels of reading proficiency. Despite poor reading outcomes, the study showed that instruction in the teaching of reading generally received little attention from leadership and managers; was under-prioritised in professional development; and teachers were unaware of how

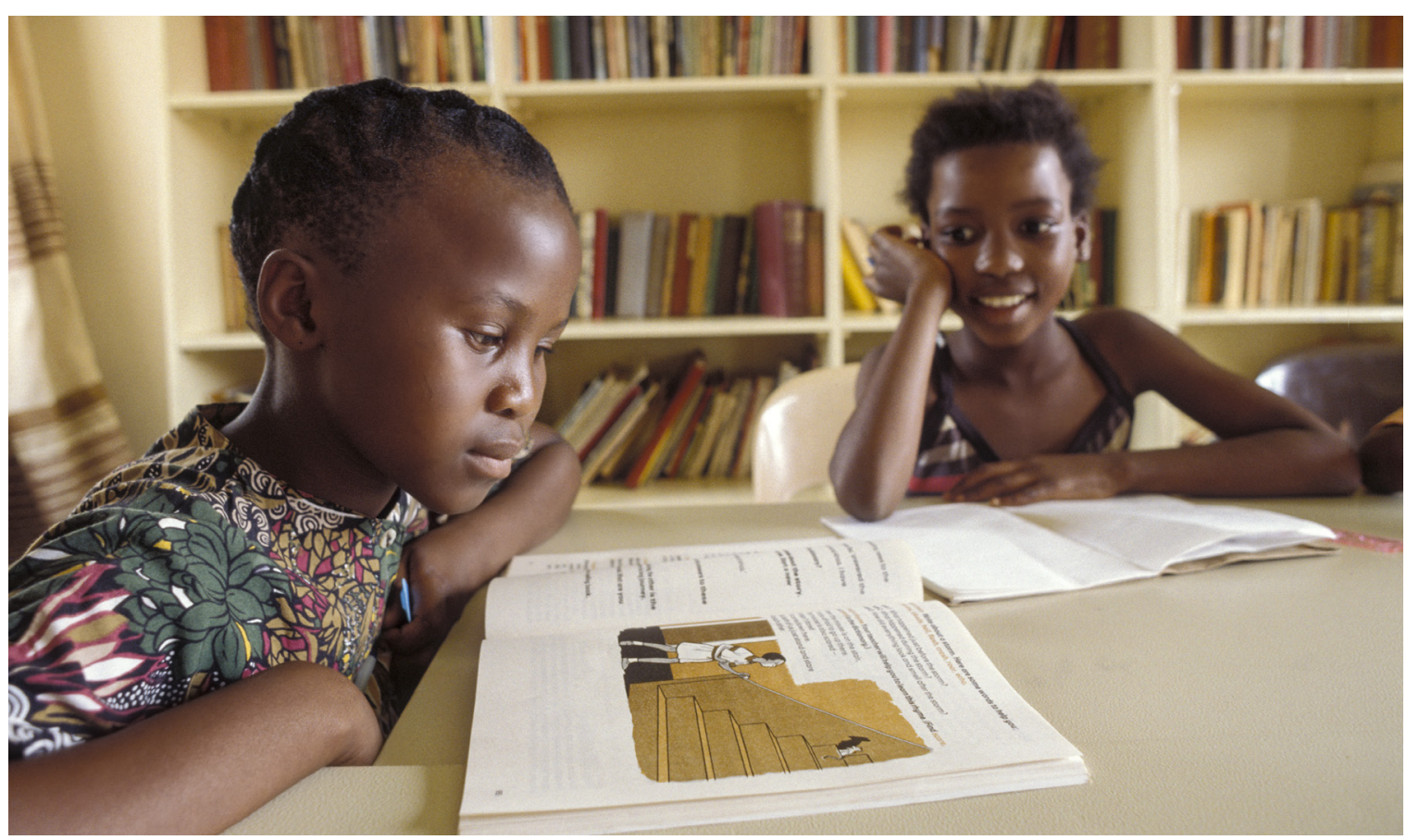

Photo: South Africa. Children reading in class. Credit: Chris Sattlberger/Panos Pictures. 
poorly children could read. Using these results, the team was able to establish tentative benchmarks in the three South African languages.

It was clear that grade 3 children were not reaching well-established norms regarding English: by the end of the academic year, half of the study sample were reading less than 34 words correct per minute (WCPM). By comparison, children in the USA are expected to read 110 WCPM by the end of grade 3 . However, these English benchmarks could not be used for African languages because the language structures are very different. Instead, learner scores on the comprehension questions associated with African language texts were used to develop benchmarks for each of the languages. According to the relevant benchmarks, it was found that less than 9 per cent of the Northern Sotho sample and less than 39 per cent of the isiZulu sample were reading at the basic reading level. More work is needed to validate the accuracy of the benchmarks, and to expand to other grades and languages.

\section{THE IMPACT}

Together with earlier work undertaken by the team, the research has contributed to an increased focus at a national level on working towards benchmarks and incremental early learning targets for improvement.

On 20 June 2019, President Cyril Ramaphosa included reading for meaning in the early grades as one of the five strategic areas for South Africa to focus on in his State of the Nation Address:

Let us agree, as a nation and as a people united in our aspirations, that within the next ten years we will have made progress in tackling poverty, inequality and unemployment, where... our schools will have better educational outcomes and every ten-year-old will be able to read for meaning.

This goal was adopted partly in response to priority policy recommendations submitted by the project team, which profiled the importance of addressing reading in schools. In an earlier study, the team synthesised a large body of evidence on the binding constraints to education improvement, and the findings were presented to President Ramaphosa, highlighting that reading for meaning should become a clear priority goal for South Africa. Furthermore, the team consulted on 'The Early Grade Reading Study', led by the DBE in South Africa and funded by USAID, which further strengthened the call to scale up teacher coaching in African language reading instruction to improve reading outcomes.

Further building on the body of work, the DBE has initiated collaborations across academia, funders, and organisations (such as UNICEF, Zenex Foundation, and USAID) to develop norms and benchmarks in different African languages using existing data sets while planning for larger data collection processes to further aid this process. This comes at a time when 'reading for meaning' (a strategy to help children understand - and care about what they read) is being profiled as a national priority for the first time in post-apartheid South Africa.

Nompumelelo Mohohlwane, Deputy Director for Research, Monitoring and Evaluation at the DBE said:

\section{D}

In the absence of established reading benchmarks in the African languages, it is very difficult for the education system to identify learners at risk for reading failure during the foundation phase. It is also very difficult to set clearly articulated, realistic expectations for teachers to know the reading levels learners should attain by the end of each grade. This research is helping the Department of Basic Education initiate efforts to develop reading benchmarks in collaboration with a broad range of partners and funders.

\section{FURTHER READING}

DBE (2017) Summary Report: Results of Year 2 Impact Evaluation. The Early Grade Reading Study, Pretoria: Department of Basic Education

Spaull, N.; Pretorius, E. and Mohohlwane, N. (2018) Investigating the Comprehension Iceberg: Developing Empirical Benchmarks for Early Grade Reading in Agglutinating African Languages, RESEP Working Paper WP01/2018, Maitieland: Research on Socio-Economic Policy, Stellenbosch University

Van der Berg, S.; Spaull, N.; Wills, G.; Gustafsson, M. and Kotzé, J. (2016) Identifying Binding Constraints in Education. Synthesis Report for the Programme to Support Pro-Poor Policy Development, Maitieland: Research on Socio-Economic Policy, Stellenbosch University

Taylor, N.; Wills, G. and Hoadley, U. (2019) Addressing the "Leadership Conundrum" through a Mixed Methods Study of School Leadership for Literacy, Research in Comparative and International Education 14.1

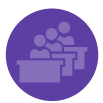
Succeeding Against the Odds: Understanding Resilience and Exceptionalism in High-Functioning Township and Rural Primary Schools in South Africa

The research team was funded by ESRC-DFID's Raising Learning Outcomes in Education Systems Research Programme, led by Principal Investigator Professor Servaas Van Der Berg, Stellenbsoch University (SU), together with Gabrielle Wills (SU), Nic Spaull (SU, Funda Wande), Nick Taylor (JET Education Services), Ursula Hoadley and Jaamia Galant (both University of Cape Town), Nompumelelo Mohohlwane (Department of Basic Education), David Carel (SU), Elizabeth Pretorius (University of South Africa), and Francine De Clerq (University of Witswatersrand).

\section{THE IMPACT INITIATIVE}

\section{For International Development Research}

The Impact Initiative seeks to connect policymakers and practitioners with the world-class social science research supported by the ESRC-DFID Strategic Partnership, maximising the uptake and impact of research from: (i) the Joint Fund for Poverty Alleviation Research, and (ii) the Raising Learning Outcomes in Education Systems Programme. We seek to identify synergies between these programmes and their grant holders, support them to exploit influencing and engagement opportunities, and facilitate mutual learning. The Impact Initiative is a collaboration between the Institute of Development Studies (IDS) and the University of Cambridge's Research for Equitable Access and Learning (REAL) Centre.

All content is available under the Open Government License v3.0, except where otherwise stated.

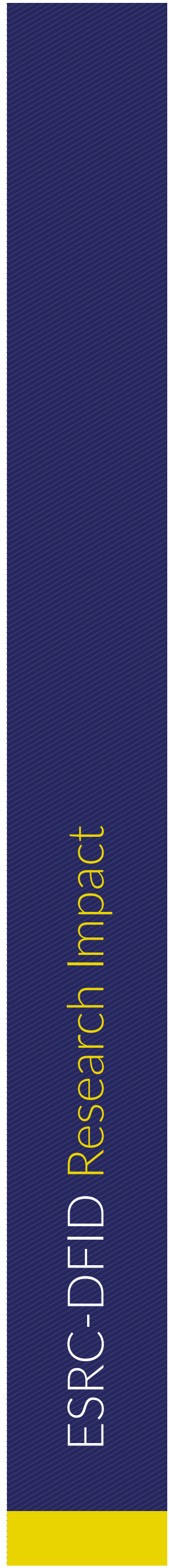

